\title{
Cardiovascular Surgery Between Makkah and Medina
}

\author{
Hassan Raffa, MD, DSc (h.c), FRCS. \\ Abdool Sorefan, FRCS (Eng.), FRCS (Ed) \\ Moustafa Sorefan, MRCP (U.K) \\ Gihad Barmada, MD \\ Samir Maher, MB. BCH, M.CH \\ DOI: http://dx.doi.org/10.5915/18-3_4-12802
}

\begin{abstract}
:
The Saudi Heart Center at the King Fahd Hospital in Jeddah, Saudi Arabia, located between Makkah (50 km) and Madina $(450 \mathrm{~km})$, receiving patients from all the parts of the Kingdom of Saudi Arabia and middle eastern countries such as Syria, Yemen, Sudan, Egypt, and others was opened in june 1981 and has performed up to this date 2481 Cardiovascular surgeries covering neonatal, pediatric and adults surgeries for congenital and acquired cardiopathies. 868 patients underwent repair for simple and complex congenital anomalies with a mortality rate of $8.6 \% .1613$ patients underwent surgery for acquired valvular and coronary heart diseases with a mortality rate of $4.0 \%$. The average mortality rate for 2481 cardiovascular surgeries in both groups (141 deaths) was 5.6\%.
\end{abstract}

Key Words: Cardiovascular Surgery, Congenital Defects, Acquired Defects, Saudi Arabia, Mortality rate.

\section{Materials \& Methods:}

2481 consecutive patients underwent cardiovascular surgery during a 4 years period. The youngest patient was 3 days old, the oldest was 72 years of age. The male/female ratio was $1.5 \mathrm{male} / 2$ female. All the patients who underwnt repair for congenital cardiac defects or coronary surgery had a preoperative detailed cardiac catheterization with complete hemodynamic data, oximetry and contrast angiography. $40 \%$ of the patients below the age of 40 years with clear mitral or aortic valve disease, without advanced pulmonary hypertension or reduced ventricular function as judged by echocardiography (percentage of shortening and ejection fraction and without associated coronary artery disease (history and EKG), have underwent open heart surgery without prior cardiac catheterization.

The Saudi Heart Center drains an area of a large patients volume reaching two and half million population, in addition of patients flying to it from Yemen, Sudan, Syria and Egypt.

The largest number of patients appearing with congenital or acquired cardiopathies are children or young adults in a rather late advanced and reduced general condition. Advanced pulmonary hypertension (above $60 \mathrm{~mm} \mathrm{Hg}$ ) (1) and congestive cardiac failure are frequent. Malnutritional state and

Saudi Heart Center and King Abdulaziz University Hospital Jeddah, Saudi Arabia

Address for Correspondence

Hassan Raffa, FRCS

Assist. Professor of Cardiac Surgery

King Abdulaziz University

P. O. Box 6615

Jeddah, Saudi Arabia hypovitaminosis is also seen in the children group. The majority of the patients are in NYHA functional class III $(80 \%)$, and $20 \%$ in class IV.

Rheumatic heart disease with its cardiac sequellae makes about $60 \%$ of the patients volume while congenital makes $35 \%, 5 \%$ is coronary artery disease! Rheumatic fever is still common in the western parts of the Kingdom (Al Baha, Gizan, Zahran, Ghamed, Taif and even in Makkah, and remains a worldwide problem in developing countries (2). Overcrowding and socioeconomic factors do play certain role in the frequent occurance of rheumatic fever in Saudi Arabia. many of the children and adults appear with multiple diathermy burn scars on their bodies reflecting long trials of unsuccessful folklore treatment by local healers which allows the disease to progress to a very advanced neglected state with severe myocardial damage. 11 children have appeared with congenital cardiac anomalies, where Eisenmenger syndrome has developed.

All patients who underwent open heart surgery had standard techniques of extracorporeal circulation employing a membrane oxygenator for major and long cases in adult and bubble oxygenator in children, as it is simple to prepare, effecient and cost effective (3). In all surgeries total bypass was applied, cold pottasium cardioplegia $(12 \mathrm{mecq} / 500 \mathrm{cc})$ used, systemic hypothermia to 28 degree C, aortic crossclamping and always left ventricular venting through an apical stab, topical cooling using slushed ice around the heart was a routine. Hemodilution was used on all adults patients. Every patient undergoing open heart surgery donated 2 litres of reqular blood by his relatives and 2 doners for fresh blood were kept for the day of surgery. Cyanotic infants are not seen frequently (4), it seems that most 
of them die at home. Tetralogy of fallot and transposition of the great arteries are the commonest. Most of the coarctation seen are periductal in type and well localized and with well developed aortae and no hypoplasia, so that an anterior qusset angioplasty of the aorta is sufficient. All the ductus arteriosus we ligated in double fashion with a transfixion expect in 6 cases, which were divided and sutured there was only one simple case of PDA recanalization due to faulty application at the first surgery.

\section{Closed Heart Surgeries for Correction of Congenitales Anomalies}

\begin{tabular}{lcc}
\hline Type & Patients No. & Death \\
\hline Patent ductus arteriosus & 177 & 2 \\
Systemic Pulm. artery shunts & 34 & 6 \\
Coarctation of aorta & 24 & 1 \\
Vascular rings & 3 & - \\
Pulmonary artery banding & 3 & - \\
Atrial septectomy for T.G.A. & 3 & 1 \\
& & $\mathbf{1 0}$ \\
Total No. & $\mathbf{2 4 4}$ & $\mathbf{4 , 0 \%}$
\end{tabular}

Congenital Cardiac anomalies are rather common in the Saudi society. Almost $40 \%$ of the cardiac patients needing surgical help are in the pediatric age group. Most of these patients appear in an advanced and neglected state with gross cardiomegaly, advanced pulmonary hypertension, congestive cardiac failure and a wasted malnutritional state with iron defeciency hypochromic anemia. Strong preoperative preparation is mandatory. An intensive care unit with 15 beds is available for open and closed heart patients.

\section{Pediatric Open And Closed Heart Surgery}

657 Surgeries for congenital Diseases

291 Surgeries for acquired diseases

948 Total patients number (under 14 years)

75 Death mortality rate $7.9 \%$

Sinus venosus Atrial Septal Defect are rather frequent and rare always associated with 1 to 2 abnormally draining pulmonary veins. 6 secundum defects were found to be associated with clefts in the anterior or more frequent the posterior leaflet of the mitral valve.

Discrete subaortic stenosis (DSS) is mostly of a fibromuscular type 1-2 mm below the aortic valve. In only 2 cases the aortic valve had to be replaced in addition to the excision of the diaphragmatic shelf. Aorto septal approach (5) or aorto ventriculoplasty for radical excision and myectomy was not used yet. The reported reccurence rate of subvalvular stenosis

\section{Open Heart Surgery for Congenital Anomalies}

\begin{tabular}{lrc} 
Type & Patients No. & Death \\
\hline Atrial Septal Defect (ASD) & 232 & 12 \\
Ventricular Septal Defect (VSD) & 142 & 14 \\
Tetralogy of Fallot (TOF) & 119 & 24 \\
Pulmonary Stenosis (PS) & 62 & 2 \\
Discrete Subaortic Stenosis (DSS) & 23 & 2 \\
Congenital Aortic Stenosis & 11 & - \\
Double Outlet Right Ventricle & 5 & 1 \\
(DORV) & 4 & - \\
Ebstein Anomaly & 4 & 1 \\
Aorto Pulmonary Window & 6 & 2 \\
Total Atrioventricular Canal & 2 & 1 \\
Total anomalous pulmonary venous & 1 & \\
return (TAPVR) & 1 & 1 \\
COR Triatriatum & 2 & - \\
Truncus Arteriosus & & \\
Dissecting Aneurysm of Ascending & 9 & 6 \\
Aorta with AR (Marfan) & & \\
Very Advanced Complex Anomalies & & $\mathbf{6 5}$ \\
\hline Total No. & & \\
Average Death Rate & & \\
\hline
\end{tabular}

is still high (6), however better results are achieved with aortoventriculoplasty than simple excision. Since discrete subvalvular aortic stenosis is rather common in Saudi Arabia (24 cases in 3 years period) we are planing to use this new proposed technique.

Advanced pulmonary hypertension more than $60 \mathrm{~mm} \mathrm{Hg}$ is a common finding in Saudi adults with Atrial Septal Defect (ASD) and Ventricular Septal Defect (VSD) due to the long duration of the disease, few patients appear with incomplete spontaneous Ventricular Septal Defect (VSD) closure with aneurysmal transformation of the septal leaflet of the tricuspid valve (7). Many of these patients do appear with multiple diathermy scars on their truncs with gross cardiomegaly and intractable heart failure, making intensive preoperative management and preparation, including correction of iron defeciency anemia, necessary. Rheumatic fever is common and rather endemic in Saudi Arabia, especially in the southern parts of the Kingdom, where the climate is rather cold and many children live together in overcrowded homes. Rheumatic fever in Saudi Arabia leads to severe damage, destruction and even calcification at an early age making valve replacements frequently necessary at an early age of childhood $(8-14, y) .(8)$

$50 \%$ of the valves are repaired using a modified Kay-Wooler method at uni or bicommissural level with pledgeted $2 \times 0$ ticron sutures. The competence of the valve is assured by injecting saline under pressure from the L.V. apex (9), calcified valves are debrided and repaired with a pericardial patch, only severely calcified or ulcerated and perforated valves are replaced (10). For aortic valve replacement only 
Open Heart Surgery for Acquired Cardiovascular Diseases

\begin{tabular}{lrr}
\hline Type & Patients No. & Death \\
\hline Aortic Valve Replacement (AVR) & 244 & 8 \\
Mitral Valve Replacement (MVR) & 291 & 14 \\
Multiple Valve Replacement & 104 & 12 \\
Mitral Valve Repair & 480 & 15 \\
Aortic Valve Repair & 18 & 1 \\
Coronary Artery Bypass & 35 & 4 \\
LA Myxoma & 2 & - \\
Thoracic Aneurysms & 2 & - \\
Heart Hydatidosis & 1 & - \\
\hline Total No. & $\mathbf{1 1 7 7}$ & $\mathbf{5 4}$ \\
Average Death Rate & & $\mathbf{4 , 5 \%}$
\end{tabular}

St. Jude and Duromedic bi-leaflets valves are used (11) and patients are kept under prophylaxis with antiplatelet agents (persantin $75 \mathrm{mg} \mathrm{tds}$ ) (12).

All patients who underwent mitral valve replacement and received mechanical valves St. Jude or duromedic are fully anticoagulated. Biologic tissue valves are implanted now noly in young women in childbearing age (13). Due to the know morbidity and mortality associated with mitral valve replacement, the Saudi Heart Center has taken a new policy as to try to repair every mitral valve, whenever possible (14).

Aortic valve replacement has a low mortality of $3,3 \%$ and embolic rate of less than $1 \%$ with bileaflets central flow valves.

Mitral valve replacement has a mortality rate of $4,8 \%$, however mitral valve repair has a lower mortality of $3,1 \%$; open mitral valvotomy is the safest with a very low mortality of $1 \%(15)$.

Closed mitral valvotomy is done only by pregnant women, who cannot be put on cardiopulmonary bypass. All mitral stenosis are being done in open method, as not only commissures but also the subvalvular apparatus can be mobilised; associated clots removed, calcium debrided, residual regurgitation repaired, competence checked and lesser rapid chance of restensosis (16) is possible with open method.

Closed Heart Surgery For Acquired Heart Diseases

\begin{tabular}{lcc}
\hline Type & Patients No. & Death \\
\hline Pericardiectomy & 15 & 2 \\
Closed Mitral Valvotomy & 2 & - \\
Peripheral Vascular Disease & 233 & 4 \\
Thoracic Surgery & 105 & 6 \\
Permanant Pacemaker & 18 & - \\
Implantation & & \\
\hline Total No. & $\mathbf{4 3 6}$ & $\mathbf{1 2 = \mathbf { 2 } , \mathbf { 7 } \%}$ \\
\end{tabular}

At the begin of our cardiac surgery programe in 1982 only bovine pericardial xenograft valves and no porcine valves at all were implanted (for ethical and religious factors) both in the aortic and mitral position. It is also documented that calcification in gluteraldehyde preserved porcine valve in children is rather rapid (17). (Children make $20 \%$ of our valvular patients volume). Bio-prosthesis were used widely due to the high morbidity potentially associated with anticoagulation in Saudi Arabia. Many patients are bedwins who live in rural areas where no prothrombine facilities are available. Many are yet illiterate and non-complaint to the drug treatment. Since 1983 we implant only mechanical valves in children and adults for aortic position without anticoagulation but only antiplatelett drugs. For mitral valve replacement full with anticoagulation. Only women in childbearing age, who wish to have children undergo mitral valve replacement with a bioprosthesis (lonescu Shiley bovine pericardial xenograft). Elderly patients, who have had a history of thromboembolism, gastric or deoudenal ulcer, systemic hypertension, chronic atrial fibrillation or very large left atria undergo also mitral valve replacement with a bioprosthesis.

Constrictive pericarditis in saudi Arabia manifests itself by massive ascites and severe congestive heart failure. The etiology was tubercullous in only half of the cases, with significant calcification, while in other half of the cases the pathology specimen showed unspecific inflammatory changes.

\section{Summary:}

2481 consequetive pediatric and adult patients underwent cardiovascular surgery at the Saudi Heart Center during the period 1981 - 1985; in the western region of Saudi Arabia. Pediatric and adult open and closed heart surgery was performed with an average mortality rate of $5,6 \%$, mitral valve repair is performed increasingly with excellent results. Mitral valve replacement is avoided whenever possible as most of our valve patients are children and young adults, who should be protected from the high morbidity and mortality related to valve prosthesis.

We extend our thanks and gratitude to all members of the Saudi Heart Center, who made Cardiovascular Surgery between Makkah and Medina a successful reality.

\section{References}

1. M. E. Debakey M., Beal. A. C., Freih. N., Mardini. M., Guinn. A., Maddox. Kl., Cardiovascular Surgery in Saudi Arabia AM. Journ. Surg. Vol.142. Sept. 1981

2. M. K. Mardini, Rheumatic fever and its cardiac manifestations in children. An update. K.F.S.H. Jour. Vol.1. 1979

3. R. Sade, D. Bartles, J. Dearing, L. Cambell, B. Loadholt, A prospective randomized study of membrane versus bubble oxygenators in children. Ann. Thorac. Surg. Vol.29. No. 6. 
June 1980 .

4. E. Wareham, J. Coggin, H. Raffa, M. Al Fagih, L. Laughlin, A. Rasi, et. al. Introduction of open heart surgery to the Kingdom of Saudi Arabia. Saud. Med. Jour. Vol.1. No. 2. 1979

5. P. Vouhe, H. Paulain, G. Bloch, D. Loisance, J. Gamain, M. Lombaert, et. al. Aortoseptal approach for optimal resection of diffuse subvalvular approach. J. Thorac. Cardiovasc. Surg. Vol.87. No. 6. June 1984

6. T. Cain, D. Campbell, B. Paton, D. Clarke, Operation for discrete subvalvular aortic stenosis J. Thorac. cardiovasc. Surg. Vol.87. No. 3. March 1984

7. J. Sommerville, Congenital Heart Disease, changes in form and function, Brit. Heart Jour. Vol.14, 1979

8. S. John, V. Bashi, P. Jairaji, S. Muralidharan, ed. Ravikumar, S. Krishnaswamy et. al. Mitral valve replacement in the young patient with rheumatic heart disease. Thorac. Cardiovasc. Jour. Vol.86. No. 2. Aug. 1983

9. H. Rastan, D. Rastan, Accurate intraoperative testing of the function of mitral and tricuspid valve. Iranian J. Surg. 1:185. 1978

10. Nunley, A. Star, The evolution of reperative techniques for the mitral valve. Ann. Thorac. Surg. Vol.37. No. 5. May 1984

11. A. Chaux, R. Gray, J. Malloff, H. Feldman, H. Sustaita, An appreciation of the new St. Jude valvular Prosthesis Ann.
Thorac. Surg. Vol.81. No. 2. Feb. 1981

12. G. S. Weinstein, C. Mavroudis, P. Ebert, Preliminary experience with aspirin for anticoagulation in children with prosthetic cardiac valves Ann. Thorac. Surg. Vol.33. No. 6 June 1982

13. J. L. Larrea, L. Nunez, A. Reque. G. Aguado, R. Matarros, A. Minguez, Pregnancy and mechanical valve prosthesis, a high risk situation for the mother and the fetus. Ann. Thorac. Cardiovasc. Surg. Vol.36. No. 4. Oct. 1983

14. W. Halseth, D. Elliott, El. Walker, E. A. Smith, Open mitral commissurotomy and modern reevaluation. Thorac. Cardiovasc. Surg. J. Vol.80. No. 6. Dec. 1980

15. J. Laschinger, J. Cunningham, G. Bavman, W. Isom, F. Catinella, A. Mendelsohn, early open radical commissurotomy: Surgical treatment of choice for mitral stenosis. Ann. Thorac. Surg. Vol.34 No. 3. Sept. 1982

16. S. Nakano, Y. Kawashima, H. Hirose, H. Matsuda, Y. Shimazaki, Sato et. al Long term results of open mitral commissurotomy for mitral stenosis with severe subvalvular changes: $\mathrm{A}$ ten year evaluation

17. C. A. Guricio, P. J. Commer Ford, A. G. Rose, J. E. Stevens, M. S. Barnard, Calcification of Gluteraldehyde preserved porcine xenografts in young patients. Thorac. Cardiovasc. Jour. Vol.81. No. 4. April 1981

18. M. J. Elliot., De Leval. M., Valve replacement in children. W. Jour. Surg. Vol.9. No. 658. August 1985

\section{Illustrations}

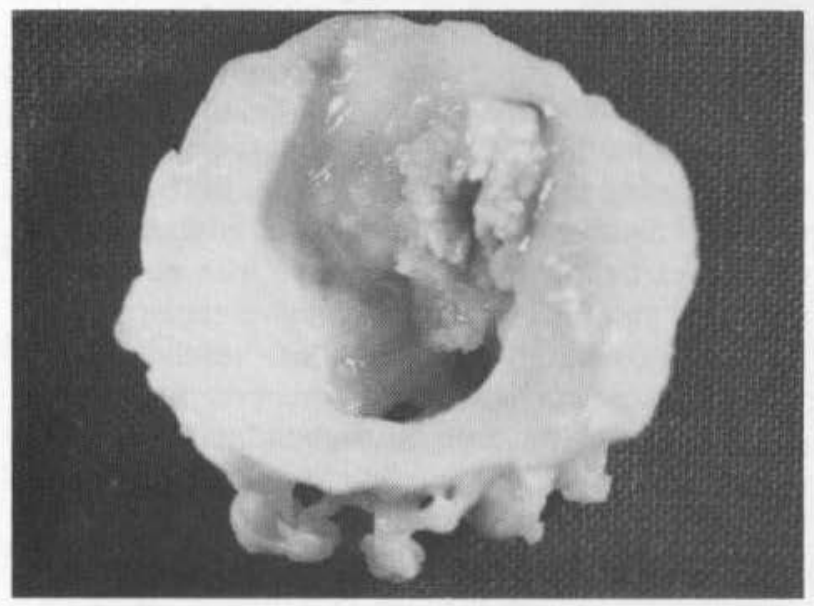

Calcified mitral Valve excised from the heart of a 9 year old Saudi boy.

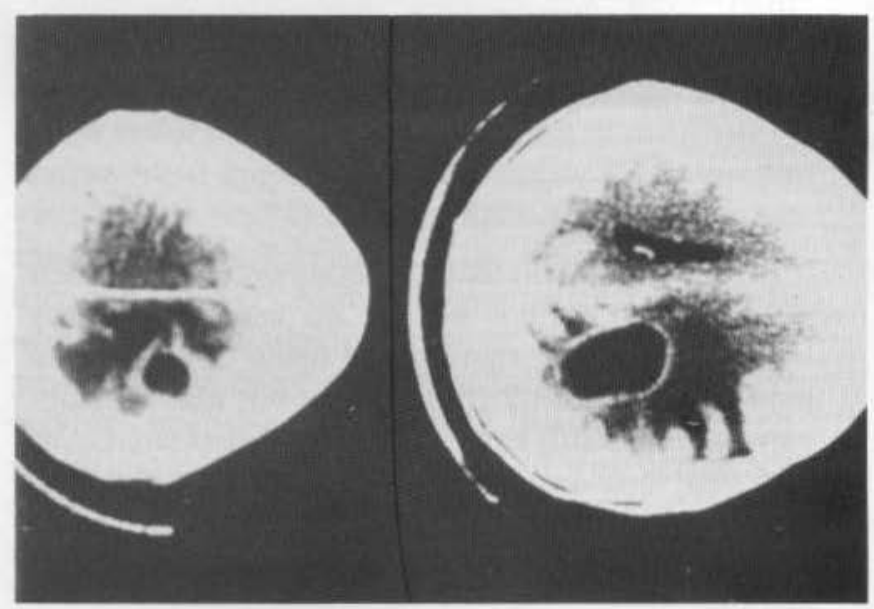

CT scan showing cerebral abcess in the brain by a young adult Saudi with Tetralogy of Fallot. 